\title{
Uma nova abordagem à educação
}

Pablo Kyoshi Rocha ${ }^{1}$

HORN, Geraldo Balduíno; GERMINARI, Geyso Dongley. O ensino de história e seu currículo - teoria e método. Petrópolis, Rio de Janeiro: Vozes, 2013.

ARENDT, Hannah. Crise na educação. Disponível em: http://www.gestaoescolar.diaadia.pr.gov.br/arquivos/File/otp/hanna_arendt_cri se_educacao.pdf

O livro de Geraldo Balduíno Horn e Geyso Dongley Germinari se encaminha para uma observação nas mudanças que ocorreram na política educacional da década de 80 , junto ao bojo, a afirmação da pedagogia histórico-crítica e o "seu papel no contexto social, político e econômico" p.07.

O seu foco é sobre "a necessidade de renovação, a concepção e a metodologia do ensino nos vários campos do conhecimento humano" p.07, em especial, o currículo no ensino de História. Na proposta teórica de Antonio Gramsci, eles chamam atenção a respeito da necessidade de

\footnotetext{
${ }^{1}$ Graduando do $4^{\circ}$ ano do curso História Bacharelado, da Universidade Estadual de Ponta Grossa (UEPG).
} 
formação de novos intelectuais, ligado diretamente à produção e na atuação de avanços pedagógicos no cenário da educação brasileira, e apostam nos estudos de teoria em história e a possibilidade no avanço que se refere à metodologia do ensino. Gramsci aponta que a "escola unitária não deve empenhar-se em uma formação estritamente profissional buscando atender o mercado de trabalho; ao contrario, deve ser formativa, de cultura geral humanista" p.09, a meu ver, se trata de uma crítica à comercialização da educação, onde o melhor ou mais bem preparado será a melhor opção, logo se cria uma pirâmide de desempenho para integrantes de mesma categoria, a criança que esta em processo de educação, que deveria adquirir certos hábitos valores e atitudes, acaba sendo corrompido (sei que esse termo não é o mais correto) com a inserção de valores mercadológicos e políticos; Hanna Arendt, no seu ensaio "A Crise Na Educação", aponta que as "escolas [nesta parte, menciona apenas escolas americanas, por ser uma terra essencialmente de imigrantes, expostos em um contexto patriótico] são necessariamente levadas a assumir funções que, em qualquer estadonação, seriam naturalmente desempenhadas em casa", ou seja, escola desempenhando função social e política.

No primeiro capítulo os autores buscaram explicar a questão das teorias críticas e da questão do currículo na renovação do saber histórico. Os estudos sobre currículos permaneceram letárgicos até a década de 70 e passaram por mudanças somente depois de uma análise 
marxista, possibilitando, através da dialética, novos estudos sobre o tema. Para entender o currículo em sua plenitude, é indispensável um resgate das fundamentações históricas, análise de suas origens, discordâncias internas e tendências na concepção para o futuro. O currículo sempre foi cuidado como objeto, fruto do conhecimento que foi chamado de "científico", e que por sua vez, é "parcial", pois o conhecimento está ligado ao processo histórico-cultural e representa a "hegemonia e as relações sociais" [construção social].

Em meio a esta discussão que acerca o conhecimento, a principal pauta é sobre o conhecimento estratificado, em que alguns componentes são levados como alto "status", sendo alvos de seleção por prestígio. Logo, entende-se o que é tomado por conhecimento e o que é deixado de lado, um exemplo citado pelos autores é a figura hierárquica do professor e a subordinação do aluno. Esta parte se encaixa perfeitamente na análise feita por Arendt, envolvendo a política e sua presunção, "em vez de um indivíduo se juntar aos seus semelhantes assumindo esforço de os persuadir e correndo risco de falhar, opta por uma intervenção ditatorial, baseada na superioridade de um adulto". Ambos os pontos de vista apontam para a mesma direção, o modelo de educação mantido e sustentado pelo Estado, em que está préestabelecido à relação pedagógica, o espaço e o tempo.

O modelo de currículo e educação esta intrinsicamente ligado ao modo econômico capitalista. Em uma sociedade que a meta é acumular 
capital, a lógica de acumulação também se executará no meio político e cultural, portanto, outros aspectos desse sistema também serão incorporados, como por exemplo, o crescimento individual, a sacralização dos grupos dominantes, o aumento de rendimento e a competição entre currículos, e isso também se aplica ao sistema de educação dessa sociedade. Em outras palavras, temos um "capitalismo educacional" estruturado, e para romper com esse modo seria necessário repensar a educação, esclarecendo suas noções, uma vez que o ensino deve estar ligado com o processo social.

O objeto da história é dividido em uma tríade: poder, cultura e trabalho. Em um viés marxista, o poder tem como finalidade familiarizar as relações de produção e dominações de classes, reciclando-a continuamente. Sabendo que o poder assume uma postura economicista, os autores lançam uma pergunta "o que significa o poder enquanto categoria organizadora de uma proposta curricular de História?"p.33; o poder está difuso na sociedade e se institucionaliza no Estado, e por sua vez reproduz a dominação de classes, essa dominação é mediada por relações de poder que as pessoas naturalmente estabelecem entre si, ocorrendo geralmente em praticas coletivas, como família, escola, instituição, etc. Cabe à historiografia identificar o poder e as suas relações de interdependência que se constituem.

A cultura abordada pela concepção do materialismo histórico renovado é entendida como uma criação humana frente à natureza, e 
não pode ser entendida como outro lugar da realidade ou reflexo da realidade, ela é a própria realidade. A concepção de cultura assumida pelo currículo é vista como uma "produção material" e como um "símbolo", neste sentido "o que significa ter a cultura como categoria para o ensino de História?"p.35. Há dois enfoques, a primeira é a cultura vista como aspecto de uma determinada realidade social e a segunda é cultura enquanto conhecimento, ideais e crenças da forma como aparecem na vida social. "A cultura é um processo pelo qual o homem acumula experiências que vai sendo capaz de realizar"p.38.

O trabalho, sob a orientação do materialismo histórico, é o principal elemento modificador de uma sociedade, pois impulsiona o processo de formação, desenvolvimento e transformação do modo de produção da existência humana, e que por sua vez "humaniza a natureza e se humaniza, autoproduzindo-se" p.41. Dessa forma o homem, através do trabalho, se transforma e transforma o meio em que vive, dominando-a e acumulando experiências, o resultado disso são as criações humanas: teorias, ciências, saber e história. Por isso, o trabalho deve ser entendido como um precursor da discussão metodológica do ensino de história.

No segundo capítulo eles tratam das abordagens metodológicas do ensino de História, nele se empenham em mostrar o tempo como categoria fundamental do currículo. No currículo, houve um mal entendido quanto à abordagem, o que resultou em uma má estruturação 
dos conteúdos, que partem do pressuposto de que é possível trabalhar os conteúdos por varias interpretações de tempo. Caso o tempo passe a ser tomada como ligamento, a história passará a ser articulada pela via cronológica.

"A cronologia é a datação" p.51 que feita com base no calendário e o historiador passou a usá-lo para datar acontecimentos, dessa forma foi possível trabalhar com acontecimentos que não estavam datados de acordo com a cronologia estabelecida, é necessário entender que existem outras sociedades vivendo paralelas a nossa sem ter referência à cronologia. Não é errado considerar a cronologia como categoria fundamental, no entanto, é necessário observar seu fundamento teórico e não concebê-lo como único caminho de ensino. $\mathrm{O}$ que é correto, portanto, é entender a cronologia como categoria temporal da teoria da História.

A escola faz parte do currículo e deve propiciar um âmbito em que o aluno esteja exposto a transmissão e assimilação do conhecimento. Sabendo disso, o professor, por sua vez, é o responsável enquanto figura simbólica de poder e de maior intelecto, pelo processo de produção de conhecimento através método dialético. O currículo é organizado por conteúdos, pensar na estrutura curricular significa pensar no que a escola ensina, e o saber escolar se manifesta através do currículo, entendi essa parte como um ciclo de recompensa - em que um compensa o outro. Na crítica de Hannah Arendt, denotam maior 
importância ao conhecimento contido no currículo do que em qualquer outra atividade extracurricular.

E "como fica o saber escolar com relação ao ensino de História propriamente dito?" p68. Entender a história é entender as transformações sociais provocadas pelas intervenções humanas na natureza, e isso só será entendido a partir de um procedimento metodológico que entenda a história, não como um saber pronto, mas a partir de sua construção.

Em relação à pesquisa, deve integrar como base no processo metodológico e incorporado como prática, presente em toda a ação educativa. A inserção de documentos como fontes de pesquisa contribuirá diretamente na produção do conhecimento, colaborando e melhorando com o ensino docente na transmissão de conhecimento didático.

Sobre a tematização da história, debate-se muito sobre a renovação da disciplina, de forma que a intenção seja solucionar os problemas que acercam a teoria curricular. O modelo francês de história, que é a divisão por temas, surgiu como referência para a educação básica, ou seja, o modelo francês é a base do currículo do ensino em história. Não há como negar que há um esforço em tentar mudar o cenário atual, mas não podemos esquecer que a estrutura educacional esta categorizada por "anos" - segundo Hannah Arendt, a escolaridade obrigatória se estende até a escola secundaria, dezesseis 
anos, uma espécie de continuação da escola primaria, portanto seria necessário uma restruturação total do sistema educacional.

Sobre o terceiro capítulo, historia local, arquivos familiares e o ensino, há uma preocupação em relação à reconstrução de memória local, como cenários, municípios, áreas geográficas, etc. e o ponto chave seriam os documentos familiares. Segundo os autores, esse tipo de história se empenharia em contar a história do jeito que ela é, longe das máscaras colocas por elites locais, ou histórias forjadas eliminando aquilo que não os interessassem. A pesquisa de história local não é uma novidade, inclusive é um dos campos de pesquisa para acadêmicos em história. O interesse se volta para uma abordagem social, que tem a intenção de restaurar as relações sociais de determinadas localidades, por outro lado, não podemos analisar o tempo a partir, somente, das relações sociais, sem que haja um aprofundamento teórico metodológico que consiga unir o contexto e o ponto de vista do observador.

Os autores deixam claro quanto ao uso do documento como fonte, mas essa não é a única forma possível de se ter contato com o passado, essa quebra de visão aconteceu na década de 30, com a formação da Escola Nova. Nele, o aluno foi colocado como o centro e o professor como o seu orientador, com o objetivo de induzir os alunos ao uso de documentos, muito semelhante ao que acadêmicos de história praticam em sua graduação. Os documentos focos não envolvem 
conjuntos documentais de pessoas que se tornaram personalidades, dito como ilustres, mas sim daquele documento de fundo de gaveta, amarelados, esquecido, que para os autores, esta seria um caminho para reconstruir o ensino de história.

Este tipo de pesquisa seria de grande importância, pois, resgata costumes e cotidianos, valoriza a micro historia e inclui histórias que não foram contempladas pela história tradicional. Se o objetivo é o resgate dessas "micros-historias", o uso e manuseamento de fontes orais são de suma importância, pois serão eles que darão formato à fonte pesquisada e ligarão as demais informações dos documentos.

O ensino de História e seu currículo cumpriram o seu papel ao tratar especificamente de cada um dos objetos abordados, com profundo embasamento teórico e bibliográfico. É triste dizer que ainda nos dias de hoje, e talvez nos próximos 50 anos, o ensino de história e o currículo permaneceram/permanecerá em estado quase que imutável, salvo as universidades que diferem um pouco da estrutura de ensino de todo o Brasil. Quando digo imutável, refiro-me ao currículo e ao método de ensino na educação básica, pois vemos cada vez mais as nossas indignações se tornarem uma parte encrostada a um sistema que já deveria ter passados por mudanças, não por falta de insistências, mas pelo próprio sistema desejar a sua permanência.

Recebido em 11/12/2015, aceito para publicação em 09/05/2016 